ORIGINAL ARTICLE

\title{
Outcome of antenatally suspected congenital cystic adenomatoid malformation of the lung: 10 years' experience 1991-2001
}

\author{
J K Calvert, P A Boyd, P C Chamberlain, S Said, K Lakhoo
}

Arch Dis Child Fetal Neonatal Ed 2006;91:F26-F28. doi: 10.1136/adc.2004.068866

See end of article for authors' affiliations

Correspondence to: Dr Calvert, Neonatal Unit, John Radcliffe Hospital, Oxford OX3 9DU, UK: jenny.calvert@ doctors.org.uk

Accepted 29 June 2005 Published online first 30 August 2005 he outcome of antenatally suspected congenital cystic adenomatoid malformation Objective: To determine the outcome of antenat
of the lung (CCAM) over a 10 year period.

Methods: This is a retrospective study of all babies diagnosed antenatally in the Prenatal Diagnosis Unit and delivered in Oxford between 1991 and 2001. Data were obtained from the Oxford Congenital Anomaly Register, theatre records, and histopathology reports.

Results: Twenty eight cases of CCAM were diagnosed antenatally. Five pregnancies were terminated. Data are available on all 23 of the pregnancies that continued and resulted in two neonatal deaths and 21 surviving babies. Eleven of the 23 cases (48\%) showed some regression of the lesion antenatally, and four of these cases appeared to resolve completely on prenatal ultrasound. Three of the 23 babies (13\%) were symptomatic in the early neonatal period, and three developed symptoms shortly afterwards. Seventeen of the 23 babies (74\%) were asymptomatic, of whom 12 had abnormalities on chest radiograph or computed tomography scan and had elective surgery. Two babies (8\%) had completely normal postnatal imaging, and three had abnormalities which resolved in the first year of life. Seventeen of the 23 babies (74\%) had surgery. Histology at surgery was heterogeneous. Of the 23 live births, all 21 survivors (91\%) are well at follow up or have been discharged.

Conclusions: All babies diagnosed antenatally with CCAM require postnatal imaging with computed tomography irrespective of signs of antenatal resolution. In asymptomatic infants, the recommendations are close follow up and elective surgery for persistent lesions within the first year of life. Histology at surgery was heterogeneous, and this should be considered when counselling parents.
C ongenital cystic adenomatoid malformation of the lung (CCAM) is a form of congenital cystic lung disease believed to result from an arrest in fetal lung development. ${ }^{1-3}$ There has been an increase in cases suspected prenatally over the last decade. Antenatal ultrasound findings suggestive of CCAM include an increase in lung echodensity with or without associated cyst formation. Hydrops may occur in the most severe cases. The differential diagnosis includes lobar sequestration or congenital diaphragmatic hernia. ${ }^{4-6}$

CCAM is usually restricted to a single lobe and occurs in isolation. ${ }^{7}$ Associated anomalies are rare. An incidence of 1 in 25000 live births has been suggested, ${ }^{8}$ with males and females equally affected. Potential clinical outcomes associated with CCAM are as follows. Antenatally it can lead to hydrops, polyhydramnios, or regress. ${ }^{9}$ Postnatally the baby may have severe respiratory distress, or more commonly be asymptomatic. ${ }^{8}{ }^{10-13}$ Traditionally, surgery is recommended to remove the CCAM because of the long term risks of morbidity from infection, pneumothorax, or, more rarely, malignancy. ${ }^{14-18}$

The aims of this study were to document the outcome of all babies diagnosed antenatally with suspected CCAM over a 10 year period from 1991 to 2001 in order to facilitate counselling of parents during pregnancy and to allow optimal timing of postnatal management.

\section{METHODS}

A retrospective audit was carried out of all babies diagnosed in the Prenatal Diagnosis Unit and delivered at the John Radcliffe Hospital, Oxford between 1991 and 2001. Data were obtained from the Oxford Congenital Anomaly Register, theatre records, and histopathology reports, to identify all babies with a diagnosis of CCAM. Information on gestation at diagnosis, progression of the lesion during pregnancy, the presence of other anomalies, postnatal features, results of postnatal investigations, and outcome were recorded. Ethical permission was not required for this study.

\section{RESULTS}

Figure 1 illustrates the overall results of the study. Of the pregnancies that continued, data are available on all 23 babies, two of whom died in the neonatal period and 21 are alive and well. Table 1 shows the characteristics of these 23 babies. All 21 babies who survived had postnatal imaging with chest radiograph and computed tomography (CT) scan.

After delivery, three babies were symptomatic, and three developed symptoms later in the first year of life at 2 weeks, 8 weeks, and 5 months. There were two neonatal deaths: one baby previously noted to have massive ascites which resolved, born at 36 weeks gestation with a type 3 CCAM, on the right, who died at 2 hours of age and was found at post mortem examination to also have right bronchial atresia and a hypoplastic left lung; the second baby was born at 35 weeks gestation and had a large CCAM with hydrops. Despite surgery, he died on day 9 with complications from multiple air leaks.

Seventeen babies (74\%) were asymptomatic after birth. Of these, $12(71 \%)$ had abnormalities which were detectable on postnatal imaging and went on to have elective surgery. Two babies had their diagnosis changed on the basis of postnatal

Abbreviations: CCAM, congenital cystic adenomatoid malformation of the lung; $\mathrm{CT}$, computed tomography 


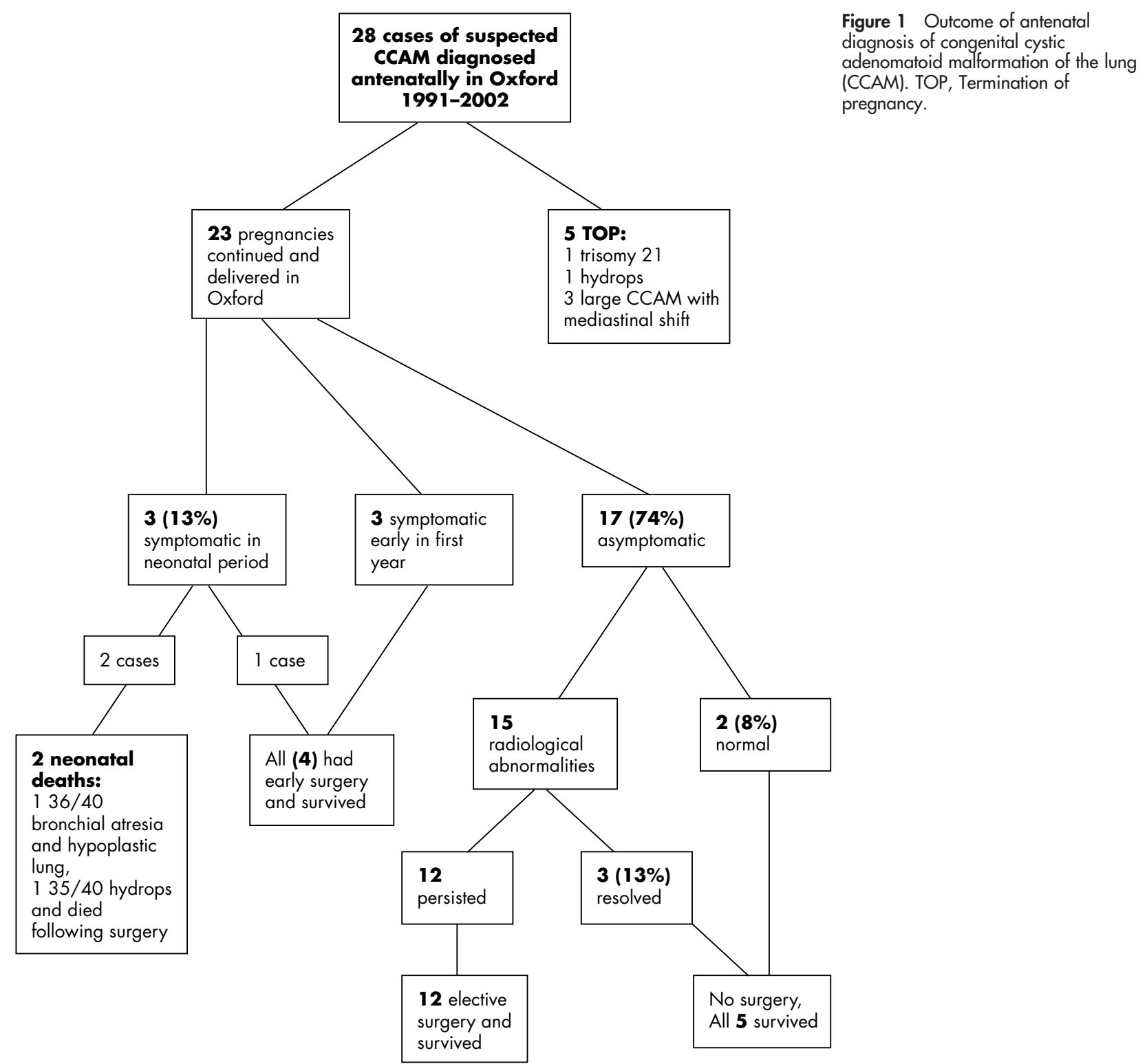

imaging to lobar sequestration and a bronchogenic cyst respectively. Five of the 17 asymptomatic babies (29\%) did not require surgery. Of these five babies, two had chest

Table 1 Characteristics of babies born after antenatal diagnosis of congenital cystic adenomatoid malformation of the lung

\begin{tabular}{ll}
\hline Gestation (weeks) & $39(35-42)$ \\
Birth weight (g) & $3583(2640-4674)$ \\
Sex & $13(57 \%)$ \\
$\quad$ Male & $10(43 \%)$ \\
$\quad$ Female & $9(39 \%)$ \\
Unilateral & $14(61 \%)$ \\
$\quad$ Right & $0(0 \%)$ \\
Left & $2(8.7 \%)$ \\
Hydateral & $16(70 \%)$ \\
Mediastinal shift & $11(48 \%)$ \\
Antenatal regression & $2(8.7 \%)$ \\
Complete antenatal resolution & $(\mathrm{n}=23)$. \\
\hline
\end{tabular}

radiograph and CT scans reported as normal in the postnatal period, one baby had a normal chest radiograph and an area of volume loss on the CT scan, but no identifiable abnormality, and two babies had normal chest radiograph and changes on CT scan, which resolved by 9 months of age. Four of these five babies were followed up for 12-17 months and were well at discharge.

Overall, 17 babies had surgery. Sixteen of these survived. Timing of surgery ranged from two days to 23 months with a median of eight and a half months. Histology from surgery was heterogeneous. There were nine cases of isolated CCAM, two of adenomatoid changes within a sequestered lobe, one bronchogenic cyst which had been diagnosed on postnatal magnetic resonance imaging scan at 5 months of age, three cases of isolated lobar sequestration, one of which was diagnosed on postnatal CT scan, and two cases where the histology was of bronchial malformation, not typical of either CCAM or sequestration, with areas of collapse and air trapping.

All 21 survivors (91\%) are well at follow up or have been discharged from hospital follow up at between 1 and 3 years of age. 


\section{What is already known on this topic}

- Congenital cystic adenomatoid malformation is a congenital abnormality of the lung believed to result from an arrest in fetal lung development

- There is a spectrum of outcomes associated with this condition

\section{DISCUSSION}

CCAM is an important diagnosis that can be suspected on routine antenatal ultrasound. It has implications for both the ongoing pregnancy and the baby, at delivery and later in life. Although the prognosis is generally good, this study illustrates the spectrum of potential outcome for babies with this diagnosis, ranging from hydrops and severe respiratory distress with pulmonary hypoplasia, to resolution of the lesion either antenatally or postnatally. In this study, as noted by others, ${ }^{13}{ }^{19}$ a poor outcome was associated with the presence of hydrops and prematurity. It is important that, when this diagnosis is made antenatally, parents are made aware of all potential outcomes and the need for ongoing surveillance in the pregnancy. Ultrasound scanning is subjective, and the findings often non-specific and therefore follow up scanning is important both to confirm a diagnosis and to document any changes in appearances of the lesion.

Although some lesions do resolve antenatally and most babies are asymptomatic at birth, we would recommend that all babies are investigated in the neonatal period with CT scan, even if the lesion appeared to resolve completely antenatally. We document two cases of complete antenatal resolution with normal postnatal investigations, and two cases in which, although the CCAM was not seen late in pregnancy, postnatal investigations confirmed the initial diagnosis. It is also important to distinguish where possible CCAM from lobar sequestration on postnatal imaging to ensure optimal management.

Most lesions do persist in the first year of life and therefore surgery is recommended. However, we have documented three cases in which abnormalities on postnatal imaging resolved by 9 months of age. We would therefore advocate a close follow up of asymptomatic babies, with repeat imaging and surgery for persistent lesions within the first year of life. If symptoms develop at any stage, surgery would need to be considered earlier.

The histology at surgery was variable, with some babies having their diagnosis changed to lobar sequestration. This should be considered when counselling parents antenatally. The non-specific term congenital lung malformation may be more useful when discussing the diagnosis with parents antenatally, as has been suggested by Bush. ${ }^{20}$

In conclusion, this paper provides valuable information for parents and recommendations for timing of surgery in asymptomatic patients diagnosed antenatally with CCAM.

\section{ACKNOWLEDGEMENTS}

We acknowledge Dr Mary Anthony for her support and guidance for this study.

\section{Authors' affiliations \\ J K Calvert, Neonatal Unit, John Radcliffe Hospital, Oxford OX3 9DU, UK}

\section{What this study adds}

- Most cases persist and are present after birth, although most babies are asymptomatic

- In those cases where the lesion persists, surgery is required to remove the abnormality because of the long term risks of infection, pneumothorax, and, more rarely, malignancy

P A Boyd, National Perinatal Epidemiology Unit, University of Oxford, Oxford OX3 7LF

P C Chamberlain, Prenatal Diagnosis Unit, Women's Centre, John Radcliffe Hospital

S Said, K Lakhoo, Department of Paediatric Surgery, John Radcliffe Hospital

Competing interests: none declared

\section{REFERENCES}

1 Stocker JT, Madewell JE, Drake RM. Congenital cystic adenomatoid malformation of the lung: classification and morphologic spectrum. Hum Pathol 1977;8:155-71.

2 Olsen JL, Mendelsohn G. Congenital cystic adenomatoid malformation of the lung. Arch Pathol Lab Med 1978;102:248-51.

$3 \mathrm{Ch}^{\prime}$ in $\mathrm{KY}$, Tang MY. Congenital cystic adenomatoid malformation of one lobe of a lung with general anasarca. Arch Pathol 1949;48:221-9.

4 Adzick NS. Fetal thoracic lesions. Semin Pediatr Surg 1993;2:103-8.

5 De Santis M, Masini L, Noia G, et al. Congenital cystic adenomatoid malformation of the lung: antenatal ultrasound findings and fetal-neonatal outcome. Fifteen years of experience. Fetal Diagn Ther 2000;15:246-50.

6 Thorpe-Beeston JG, Nicolaides KH. Cystic adenomatoid malformation of the lung: prenatal diagnosis and outcome. Prenat Diagn 1994; 14:677-88.

7 Adzick NS, Harrison MR, Glick PL, et al. Fetal cystic adenomatoid malformation: prenatal diagnosis and natural history. J Pediatr Surg 1985;20:483-8.

8 Laberge JM, Flageole H, Pugash D, et al. Outcome of the prenatally diagnosed congenital cystic adenomatoid lung malformation: a Canadian experience. Fetal Diagn Ther 2001;16:178-86.

9 Fine C, Adzick NS, Doubilet PM. Decreasing size of a congenital cystic adenomatoid malformation in utero. J Ultrasound Med 1988;7:405-8.

10 Duncombe GJ, Dickinson JE, Kikiros CS. Prenatal diagnosis and management of congenital cystic adenomatoid malformation of the lung. Am J Obstet Gynecol 2002; 187:950-4.

11 Gornall AS, Budd JL, Draper ES, et al. Congenital cystic adenomatoid malformation: accuracy of prenatal diagnosis, prevalence and outcome in a general population. Prenat Diagn 2003;23:997-1002.

12 Van Leeuwen K, Teitelbaum DH, Hirschl RB, et al. Prenatal diagnosis of congenital cystic adenomatoid malformation and its postnatal presentation, surgical indications and natural history. J Pediatr Surg 1999;34:794-8.

13 Davenport M, Warne SA, Cacciaguerra S, et al. Current outcome of antenally diagnosed cystic lung disease. J Pediatr Surg 2004;39:549-56.

14 Ribet M, Pruvot FR, Dubos JP, et al. Congenital cystic adenomatoid malformation of the lung. Eur J Cardiothorac Surg 1990;4:403-6.

15 Giardikis S, Didilis V, Polychronidis A, et al. Spontaneous pneumothorax resulting from congenital cystic adenomatoid malformation in a preterm infant: case report and literature review. Eur J Pediatr Surg 2002;12:195-8.

16 d'Agostino S, Bonoldi E, Dante S, et al. Embryonal rhabdomyosarcoma of the lung arising in cystic adenomatoid malformation: case report and review of the literature. J Pediatr Surg 1997;32:1381-3.

17 Granata C, Gambini C, Balducci T, et al. Bronchioloalveolar carcinoma arising in congenital cystic adenomatoid malformation in a child: a case report and review on malignancies originating in congenital cystic adenomatoid malformation. Pediatr Pulmonol 1998;25:62-6.

18 Ozcan C, Celik A, Ural Z, et al. Primary pulmonary rhabdomyosarcoma arising within cystic adenomatoid malformation: a case report and review of the literature. J Pediatr Surg 2001;36:1062-5.

19 Bunduki V, Ruano R, da Silva MM, et al. Prognostic factors associated with congenital cystic adenomatoid malformation of the lung. Prenat Diagn 2000;20:459-64

20 Bush A. Congenital lung disease: a plea for clear thinking and clear nomenclature. Pediatr Pulmonol $2001 ; 32: 328-37$. 
vein PSCs placed over a 13 month period in one neonatal intensive care unit. All had been inserted in the left leg, and the inserting practitioner failed to identify malpositioning of the PSC tip on a frontal abdominal view obtained with contrast (fig lA). Radiologists later identified the probable abnormal position based on the course of the PSC, and lateral views of the abdomen on the same day of insertion showed the superficial position of the catheter tip in the anterior abdominal wall (fig 1B).

A literature review showed that most of the reported serious complications secondary to malpositioning of saphenous lines occurred with a PSC inserted via the left leg. ${ }^{1-6}$ Chen et $a l^{1}$ reported one new and three previously reported cases of paraplegia secondary to tracking of a PSC into the lumbar venous plexus from a left saphenous vein. Odaibo et $a l^{2}$ and Kelly et $a l^{3}$ reported serious neurological and respiratory complications in preterm infants from parenteral nutrition fluid in the cerebrospinal fluid via left leg PSCs. Baker and Imong ${ }^{4}$ reported abdominal wall necrosis as a complication of PSC via a left saphenous vein with the tip in a superficial abdominal vessel, and Coit and Kamitsuka ${ }^{5}$ reported similar findings, but had one case from a right leg, as did Cartwright .

Healthcare providers need to be aware of the expected projection of a normally placed saphenous PSC. The appropriate course of the left leg PSC line passes from the left femoral and iliac veins, gradually ascending and becoming more medial until joining the inferior vena cava over the right to mid spine at the L5 or L4 level. It then ascends over the right side of the spine or slightly to the right of the spine (fig lC). Lines that end below the L5 level are not likely to be in the inferior vena cava. Lines that ascend to the left of the spine may be in an anomalous inferior vena cava but may be in a vertebral vein, in an anterior abdominal wall vessel, in the aorta, or extravascular.

We believe that tracking of the PSC line into an anterior abdominal wall vein can be subtle on the frontal abdominal radiograph, and serious catheter malposition related complications can be prevented by careful comparison with the expected course on the anterior-posterior projection (fig $1 \mathrm{C}$ ). If uncertain, a lateral abdominal radiograph to verify the catheter course and tip location is needed.

S Y AlAbsi, D L Phelps

Division of Neonatology, University of Rochester School of Medicine and Dentistry, Rochester, New York, USA

N Klionski

Department of Radiology, University of Rochester School of Medicine and Dentistry

Correspondence to: Dr Phelps, Box 651 Elmwood Ave, Rochester, NY 14642, USA; dale_phelps@urmc. rochester.edu

\section{doi: 10.1136/adc. 2005.078477}

Competing interests: none declared

\section{References}

1 Chen C, Tsao P, Yau KT. Paraplegia: complication of percutaneous central venous line malposition. Pediatr Neurol 2001;23:5.

2 Odaibo F, Fajardo CA, Cronin C. Recovery of intralipid from lumbar puncture after migration of saphenous vein catheter. Arch Dis Child Fetal Neonatal Ed 1992:67:1201-3.

3 Kelly MA, Finer NN, Dunbar LG. Fatal neurologic complication of parenteral feeding through a central vein catheter. Am J Dis Child 1984;138:352-3.

4 Baker J, Imong S. A rare complication of neonatal central venous access. Arch Dis Child Fetal Neonatal Ed 2002;86:F61-2.

5 Coit AK, Kamitsuka MD. Peripherally inserted central catheter using the saphenous vein: importance of two-view radiographs to determine the tip location. J Perinatol 2005;25:674-6.

6 Cartwright DW. Central venous lines in neonates: a study of 2186 catheters. Arch Dis Child Fetal Neonatal Ed 2004;89:F504-8.

\section{CORRECTION}

doi: 10.1136/adc.2004.068866corr 1

J K Calvert, P A Boyd, P C Chamberlain, et al. Outcome of antenatally suspected congenital cystic adenomatoid malformation of the lung: 10 years' experience 1991-2001 (Arch Dis Child Fetal Neonatal Ed 2006;91:F26-8). The surname of the fourth author of this paper was spelt incorrectly; the correct name is S Syed.
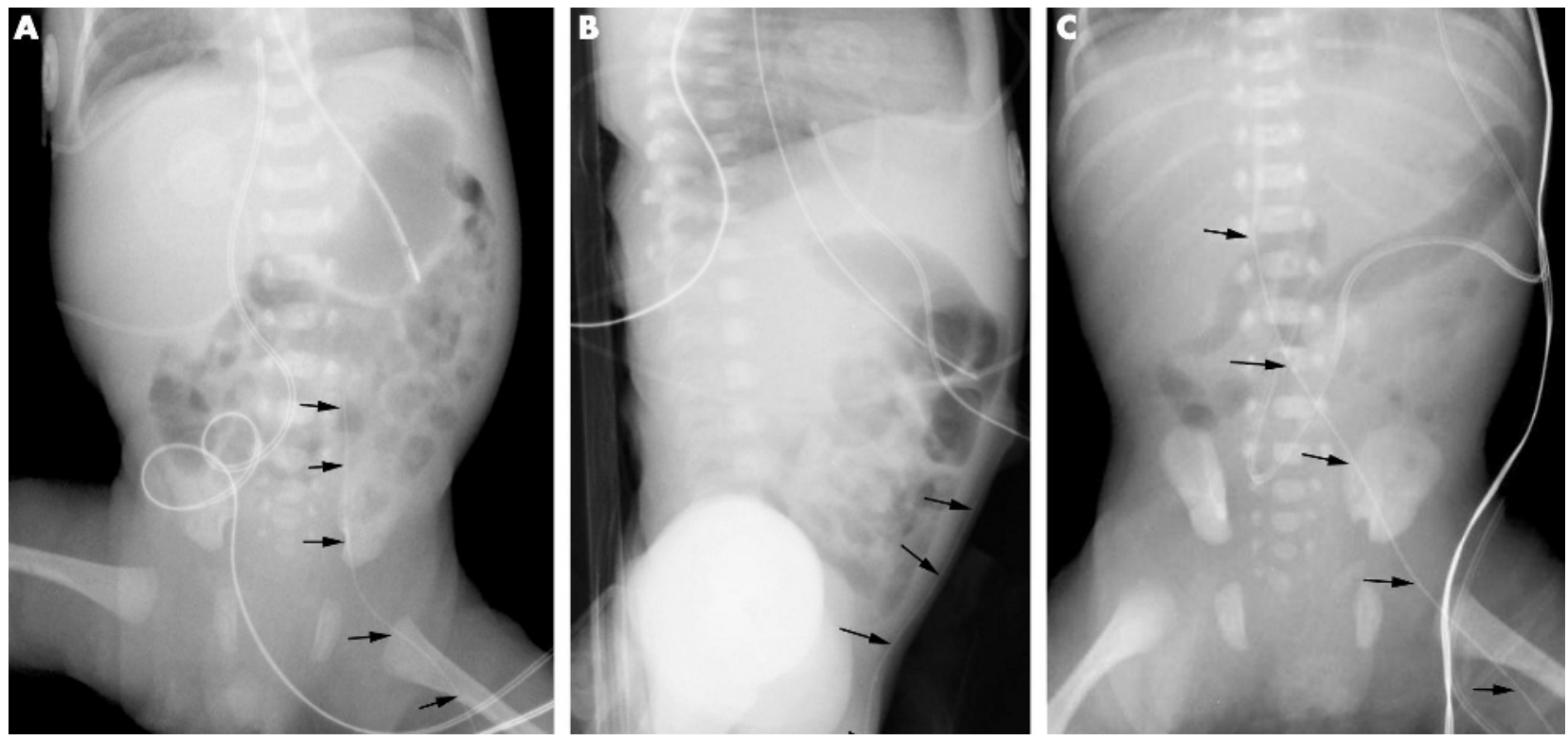

Figure 1 (A) Frontal abdominal view of malpositioned saphenous vein percutaneous silastic catheter inserted in the left leg. (B) Lateral view of the abdomen on the day of insertion showing the superficial position of the tip in the anterior abdominal wall of the catheter shown in (A).

(C) Frontal abdominal view of an appropriately positioned catheter.

\section{Pre-published book reviews}

Book reviews that have been accepted for publication but have not yet been published in the print journal can be viewed online at http://adc.bmijournals.com/misc/bookreviews.shtml 